\title{
The formation of habits in the neocortex under the implicit supervision of the basal ganglia
}

\author{
Meropi Topalidou ${ }^{1,2,3}$, Daisuke Kase ${ }^{2,4}$, Thomas Boraud ${ }^{2}$, Nicolas P Rougier ${ }^{1,2,3^{*}}$ \\ From 24th Annual Computational Neuroscience Meeting: CNS*2015 \\ Prague, Czech Republic. 18-23 July 2015
}

If basal ganglia are widely accepted to participate in the high-level cognitive function of decision-making, their role is less clear regarding the formation of habits [1,2]. One of the biggest problem is to understand how goaldirected actions are transformed into habitual responses, or, said differently, how an animal can shift from an action-outcome (A-O) system to a stimulus-response (S$\mathrm{R})$ one, while maintaining a consistent behavior. We introduce a computational model (basal ganglia, thalamus and cortex) that can solve a simple two arm-bandit task using reinforcement learning and explicit valuation of the outcome [3]. Hebbian learning has been implemented at the cortical level such that the model learns each time a move is issued, rewarded or not. Then, by inhibiting the output nuclei of the model (GPi), we show how learning has been transferred from the basal ganglia to the cortex, simply as a consequence of the statistics of the different choices (see Figure 1). Because best (in the sense of most rewarded) actions are chosen more often, this directly impacts the amount of Hebbian learning and lead to the formation of habits within the cortex. These results have been confirmed in monkeys doing the exact same task where the BG has been inactivated using muscimol. This tends to show that the basal ganglia implicitly teach the cortex in order for it to learn the values of new options. In the end, the cortex is able to solve the task perfectly, even if it exhibits slower reaction times.

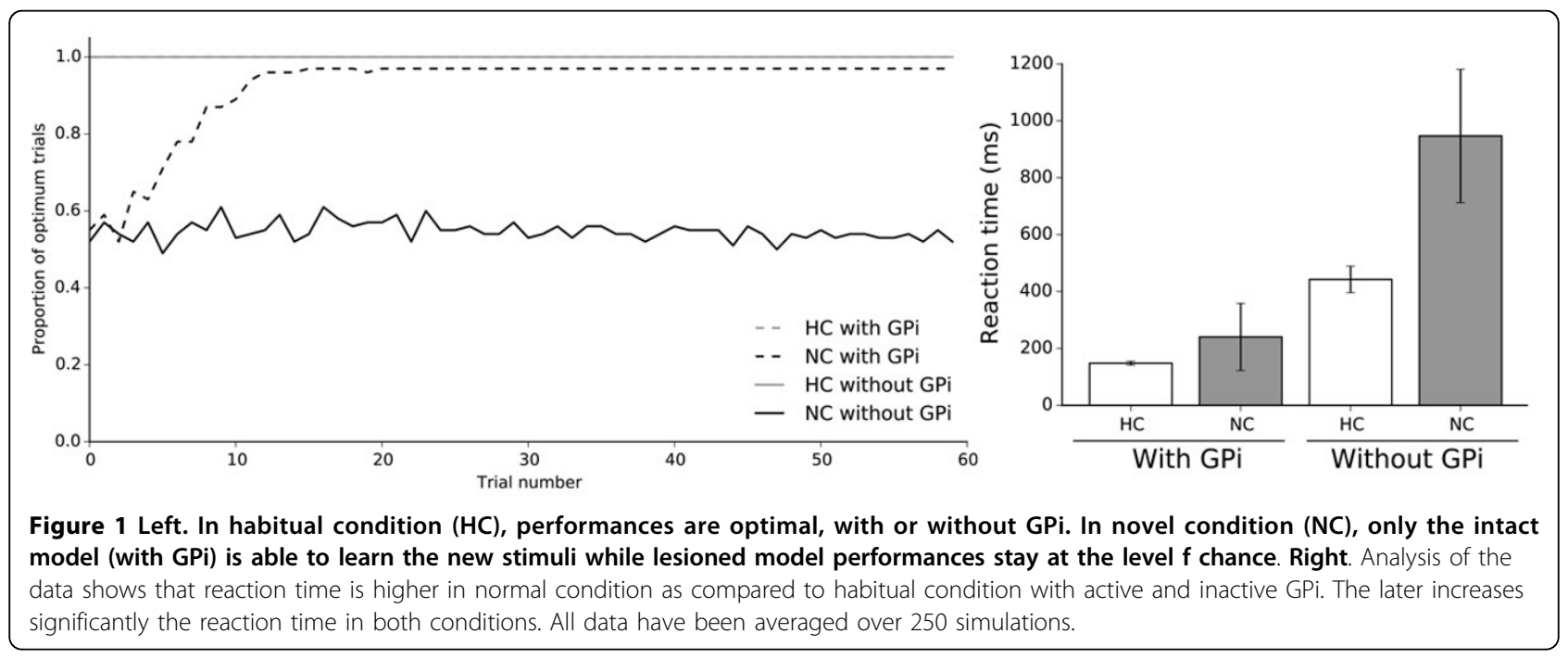

\footnotetext{
* Correspondence: Nicolas.Rougier@inria.fr

'INRIA Bordeaux Sud-Ouest, Bordeaux, France

Full list of author information is available at the end of the article
} 


\section{Authors' details}

'INRIA Bordeaux Sud-Ouest, Bordeaux, France. ${ }^{2}$ Université de Bordeaux, CNRS UMR 5293, IMN, France. ' ${ }^{3}$ aBRI, Université de Bordeaux, IPB, CNRS, UMR 5800, Talence, France. ${ }^{4}$ Laboratoire Franco-Israélien de Neurosciences, CNRS Bordeaux, Talence, Bordeaux, France.

Published: 18 December 2015

\section{References}

1. Yin $\mathrm{HH}$, Knowlton $\mathrm{BJ}$ : The role of the basal ganglia in habit formation. Nature Reviews Neuroscience 2006, 7(6):464-476.

2. Seger CA, Spiering BJ: A critical review of habit learning and the basal ganglia. Frontiers in Systems Neuroscience 2011, 5:66.

3. Guthrie M, Leblois A, Garenne A, Boraud T: Interaction between cognitive and motor cortico-basal ganglia loops during decision making: a computational study. Journal of Neurophysiology 2013, 109(12):3025-3040.

doi:10.1186/1471-2202-16-S1-P212

Cite this article as: Topalidou et al:: The formation of habits in the neocortex under the implicit supervision of the basal ganglia. $B M C$ Neuroscience 2015 16(Suppl 1):P212.

\section{Submit your next manuscript to BioMed Central} and take full advantage of:

- Convenient online submission

- Thorough peer review

- No space constraints or color figure charges

- Immediate publication on acceptance

- Inclusion in PubMed, CAS, Scopus and Google Scholar

- Research which is freely available for redistribution

Submit your manuscript at www.biomedcentral.com/submit
C Biomed Central 